\title{
LA DIGITALIZACIÓN DE LA RELACIÓN MÉXICO-CHINA MEDIANTE LA COOPERACIÓN TECNOLÓGICA
}

\author{
José Ignacio Martínez Cortés \\ Universidad Nacional Autónoma de México \\ Laboratorio de Análisis \\ en Comercio, Economía y Negocios
}

\section{HACIA UN NUEVO PATRÓN DE ESPECIALIZACIÓN}

PRODUCTIVA INTERNACIONAL

El desarrollo tecnológico ha cambiado en los últimos veinte años cualquier proceso de producción en el ámbito mundial, dejando atrás un aparato industrial obsoleto y dando paso a un nuevo sistema industrial-tecnológico en el que el valor agregado es la característica más relevante; con este proceso se accede a un nuevo estadio de producción. En el siglo XXI la ventaja competitiva duradera provendrá mucho más de las tecnologías de los nuevos sistemas y mucho menos de las tecnologías de los nuevos productos. Lo que solía ser principal (inventar nuevos productos) se convierte en secundario, y lo que era secundario (inventar y perfeccionar nuevos procesos) se convierte en principal (Thurow, 1992); estos dos factores son los que están desarrollando las siete industrias que van a marcar la pauta en el comercio internacional durante las próximas tres décadas: la microelectrónica, la biotecnología, las industrias de los materiales nuevos, la aeronáutica civil, las telecomunicaciones, la robótica, la informática y la computación (para dar paso a la telemática).

Dichas características emergen una vez que se ha consolidado el cambio tecnológico en una economía donde la ciencia industrial desempeña un papel destacado. Con el cambio de la economía internacional se está consolidando la internacionalización de la producción, 
donde pueden participar aquellas empresas que cuentan con ventajas, como capital y tecnología, con las que adquieren mayor presencia en el comercio internacional.

En años recientes la economía mundial ha tenido grandes transformaciones motivadas por la innovación tecnológica y la internacionalización del capital, con lo cual en el comercio internacional hoy predomina la exportación e importación de productos, mercancías y servicios con mayor valor agregado, en tanto han perdido presencia en los mercados internacionales aquellos países que no han logrado transformar su proceso productivo. De hecho, a partir de la década de los cincuenta el sector que más ha crecido en el comercio internacional es el manufacturero (cuadro 1), en el que se plasma la innovación tecnológica de las últimas décadas.

CUADRO 1. Expansión del comercio mundial

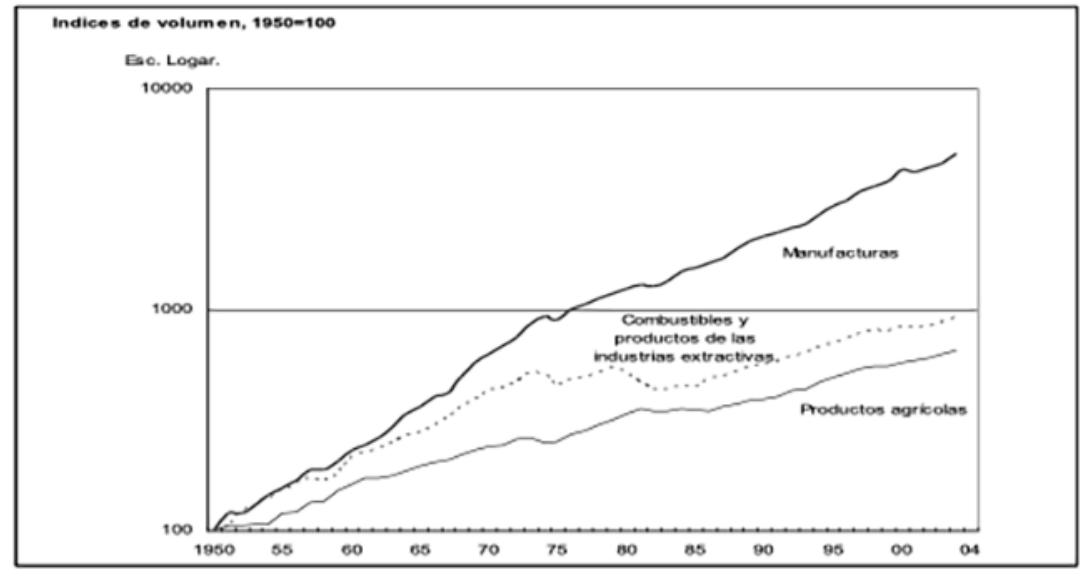

FUENTE: OMC.

En esta cuarta revolución científico-tecnológica, la robótica, la telemática, la informática y la computación dominan el cambio tecnológico, están impulsando una nueva competencia global y orillando a las naciones a adoptar nuevas políticas y estrategias industriales. La nueva competencia también se caracteriza por una nueva superestructura: cambios en la unidad productiva, su organización y su estructura administrativa (Barnet y Cavanagh, 1994). La organización de la producción se ve afectada por la tecnología, pero también modificada por las diferentes estrategias tecnológicas. Este cambio en la superestructura y la estructura industrial está siendo adoptado por países industrializados donde el legado de Taylor se ha modificado, ya que si las grandes corporaciones no se 
mantienen a la vanguardia tecnológica y administrativa quedarán al margen de la competencia global (Best, 1990).

Hoy en día, para tener mayor presencia en el comercio internacional es necesario estar a la vanguardia en tecnología. Pero no es únicamente la innovación tecnológica la que otorga esa ventaja competitiva, sino la inversión que se otorga a investigación científica, el cambio tecnológico y la formación de recursos humanos que desarrollarán investigaciones o que innovarán los cambios tecnológicos; es decir, la educación es el ramo donde los países deben invertir para el futuro desarrollo de sus propias condiciones de crecimiento. Es quizás el factor que está marcando la diferencia entre los tres grandes polos de crecimiento mundial. Por lo pronto, Japón y Alemania, y en menor medida Estados Unidos, destinan más recursos financieros a la investigación y el desarrollo.

En este cambio tecnológico con competencia global hay también divisiones, ya que en aquellos países que están en primer nivel se podran realizar investigaciones científicas e innovaciones tecnológicas; en los que se encuentran en el segundo peldaño, una producción tecnológica descentralizada; y en la tercera línea, quedan las consideradas "zonas baratas" de ensamblaje. Con este proceso de cambio tecnológico y de competencia global surge la red mundial de producción, que por medio de la innovación tecnológica da más peso a las organizaciones de "alto valor agregado" que a las de "alto volumen" (figura 1).

FIGURA 1. Nuevo patrón de especialización productiva internacional

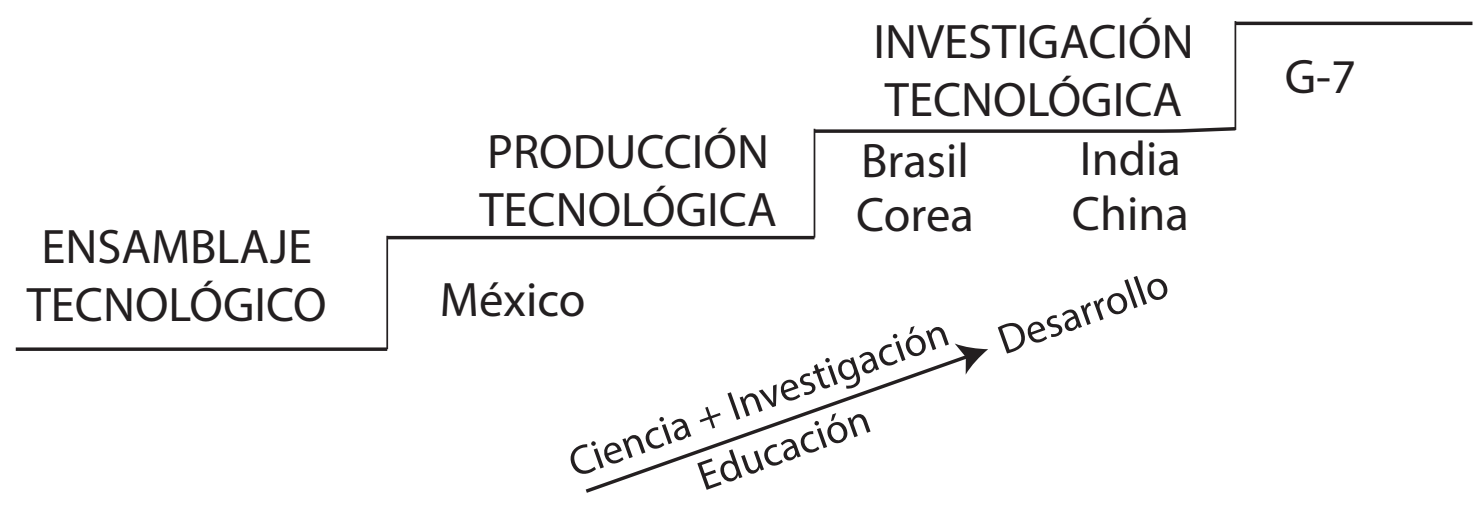

FUENTE: Elaboración propia. 
Una característica del nuevo patrón de especialización productiva internacional es el traslado de tecnologías de ensamblaje para dar paso a la transacción de un producto (Rich, 1992). Así, a partir del desarrollo de nuevas tecnologías, el comercio internacional trabaja actualmente con un proceso de relocalización de la producción mundial, ya que las empresas transnacionales procuran tener, como ventaja competitiva, una economía que les brinde una especialización, por lo que la ventaja comparativa se está basando cada vez más en la magnitud e innovación tecnológicas, así como en la capacidad para aplicar y adaptar nuevas tecnologías al proceso productivo. La era de la producción en serie es ya algo del pasado; ahora predomina la automatización y la tecnología de la información, que ofrecen productos personalizados a precios razonables en la mitad del tiempo.

\section{LA TRANSFORMACIÓN TECNOLÓGICA DE CHINA}

En diciembre de 1978, en la Tercera Sesión Plenaria del XI Comité Central del PCCh se aprobaron las directrices reformistas presentadas por Deng Xiaoping. Concretadas en el programa de las Cuatro Modernizaciones - agricultura, industria, defensa y ciencia y tecnología - y en la Política de Puertas Abiertas, se perfilaba como la única vía para situar a China entre las grandes potencias económicas mundiales, Con ello inició su reajuste, restructuración, consolidación y mejora económica (Bustelo y Lommen, 1995).

Uno de los grandes factores que transformaron a China son los grandes flujos de IED que ha tenido a partir de la última década del siglo $\mathrm{xx}$, lo que previamente requirió de un largo proceso de transformaciones económicas, políticas, sociales, tecnológicas, educativas y de investigación. Esta evolución se refleja en el marco jurídico para otorgar una atmósfera de certidumbre a los inversionistas, como es la ley de marcas de 1982 y la ley de patentes de 1984, que han brindado un marco de seguridad, aunado al ingreso de China a la Organización Mundial de la Propiedad Intelectual (OMPI) el 3 de marzo de 1980. A partir de su ingreso ha adoptado 26 leyes, 104 reglamentos y 69 tratados, relacionados con la propiedad intelectual. De igual forma, su ingreso a la Organización Mundial de Comercio (OMC) obligó a China a adoptar el Acuerdo sobre los Aspectos de los Derechos de Propiedad Intelectual relacionado con el Comercio (ADPIC).

A partir de este acontecimiento China se consolidó como el principal receptor de inversión extranjera directa (IED) del mundo en desarrollo. Hasta su adhesión a la OMC China 
ha presentado una serie de instrumentos para la atracción de IED, entre los que destacan exenciones tributarias específicas para el capital extranjero. Estos incentivos siguen vigentes en el Catálogo para la Guía de la Inversión Extranjera, en el cual se presenta una lista de industrias que se fomentan, se restringen y están prohibidas; es definido por el Consejo de Estado y por el CNDR (AgendAsia, 2013). ${ }^{1}$

Desde el principio de la reforma económica, el gobierno chino trató de utilizar adecuadamente el flujo de IED para apuntalar un modelo productivo de nuevo cuño, apoyado en transferencias de tecnología para conseguir una mejora tecnológica sustancial de las empresas chinas, obligando con ello a las compañías extranjeras a invertir con socios locales en "joint ventures". Dentro del contexto de la evolución de la economía china, la adquisición de nuevas capacidades tecnológicas y el avance tecnológico han sido las bases de su desarrollo y han hecho que hoy en día los principales líderes chinos resalten sus megaproyectos, especialmente en temas militares, como la producción de armas nucleares y de satélites, que aunada a su industria de telecomunicaciones coloca al país asiático a la vanguardia de la industria aeroespacial.

Ante este escenario, el Consejo de Estado ha puesto en marcha un número de objetivos que indica claramente el interés de China por abarcar en su totalidad el proceso de innovación, extendiendo la financiación pública y los incentivos fiscales, así como la financiación privada para las empresas innovadoras, y mejorando el sistema de protección de los derechos de propiedad intelectual, el desarrollo de estándares tecnológicos internacionales y la construcción de infraestructuras científicas, como: incubadoras, laboratorios clave, parques científicos, etcétera.

Acerca de esta estratagema de China, diversos organismos internacionales, tales como el Banco Mundial (BM), el Fondo Monetario Internacional (FMI), la Organización para la Cooperación y el Desarrollo Económicos (OCDE), la Agencia Internacional de Energía (AIE), entre otros, llaman la atención sobre la política de planeación tecnológica a largo plazo.

Sobre este tenor, el informe del Banco Mundial China 2030, y el estudio de la OCDE China 2013, pronosticaron que la inversión en ciencia y tecnología que el gobierno chino está realizando lo colocaran como una potencia exportadora de conocimiento. Al respecto, el

${ }^{1}$ China y la inversión extranjera directa, México, AgendAsia, una estrategia entre México y China, think thank. s/a. URL: http://www.agendasia.org/boletines/boletin26sep.pdf (consultado el15 de abril de 2013). 
Banco Mundial, en la publicación China 2030. Building a Modern, Harmonious, and Creative Society, afirma que este país está decidido a convertirse en una potencia global e innovadora para el año 2020 (World Bank, 2012), y para lograrlo se ha enfocado en la protección de las siguientes industrias estratégicas: energías renovables, biotecnología, tecnologías de la información, industria de gama alta y alta tecnología, mismas que son consideradas por este organismo internacional como los principales sectores del futuro crecimiento económico. Por ello, el Banco Mundial prevé una economía china más competitiva, dados los avances tecnológicos en energías renovables, el potencial de alto valor agregado y la exportación de tecnologías verdes.

Por su parte, la Organización para la Cooperación y el Desarrollo Económicos señala que desde 2009 China se ha mantenido como el segundo país que más invierte en investigación y desarrollo (I + D) (OCDE, 2013). Un año antes, para hacer frente a la crisis financiera internacional el gobierno estableció un plan de recuperación económica de un billón de dólares, de los cuales 392.7 mil millones se destinaron a infraestructura. Las inversiones se centraron en infraestructura fija y en la industria ligera, de maquinaria de fabricación, electrónica, información y petroquímica (OCDE, 2012).

los planes quinquenales X (2000-2005), XI (2006-2010) y XII (2011-2015)Las nuevas tecnologías están encaminadas a la construcción y mejora de la infraestructura, en apoyo a la energía, el transporte, las telecomunicaciones, las materias primas y los materiales de construcción.

De igual manera, el Plan Quinquenal para el Desarrollo de la Ciencia y la Tecnología 2011-2015 hace hincapié en las tecnologías clave para las industrias estratégicas, tales como la biotecnología, las tecnologías de la información y la comunicación y otros campos de alta tecnología, con la finalidad de "aliviar las presiones sobre la energía, los recursos y el medio ambiente, así como de satisfacer las necesidades de una población que envejece con productos farmacéuticos y equipo médico." ${ }^{2}$ Con este Plan, China tiene el objetivo de impulsar el consumo interno y de reorientar el desarrollo tecnológico para elevar la calidad de sus productos.

${ }^{2}$ Idem. 
En 2012 se invirtieron 26.6 mil millones de dólares para fortalecer el sistema de ciencia, tecnología e innovación mediante el desarrollo de grupos de alta tecnología y el apoyo a empresas y universidades. Por ejemplo, el Plan de Acción de Innovación Tecnológica de la Academia de Ciencias de China incluye "programas piloto de construcción (tales como una red de medios de comunicación de banda ancha inalámbrica) y la aplicación comercial de los principales resultados de ciencia y tecnología (pantallas planas)."3

El objetivo a largo plazo es elevar la productividad al relocalizar todos los factores que desempeñan un papel importante en la economía china hacia sectores más redituables. Se observa como principal artífice una innovación tecnológica propia, amigable con el ambiente. Tal premisa creará dos importantes fenómenos: i) la ruptura de la dependencia tecnológica, y ii) la reducción de emisión de dióxido de carbono. Por lo tanto China no solamente busca aumentar su productividad y competitividad, sino que también se mimetizará con el equilibrio ecológico (cuadro 2).

CUADRO 2. Retos que enfrenta China en su desarrollo tecnológico

\begin{tabular}{|c|c|}
\hline Ventajas & Desventajas \\
\hline $\begin{array}{l}\text { Evolución en la calidad de sus } \\
\text { manufacturas. } \\
\text { Innovación a partir de su mejoramiento } \\
\text { educativo. } \\
\text { Fácil penetración al mercado global } \\
\text { (Huawei, ZTE, Suntech, Lenovo, } \\
\text { etcétera). } \\
\text { Cultura empresarial en el delta del río } \\
\text { Perla. } \\
\text { Capacidad de expansión del sector } \\
\text { servicios. }\end{array}$ & $\begin{array}{l}\text { Ineficiencia de las empresas estatales. } \\
\text { Falta de comunicación entre los institutos de } \\
\text { investigación y las industrias. } \\
\text { No existe una verdadera colusión entre las } \\
\text { firmas chinas y las empresas transnacionales. }\end{array}$ \\
\hline
\end{tabular}

FUENTE: Elaboración propia con base en los planes quinquenales IX, X y XI.

Por lo anterior, el gobierno chino está realizando una serie de cambios para impulsar un desarrollo sustentable. "El crecimiento económico de la nación demuestra una excesiva dependencia hacia el consumo de energía y recursos con altos costos ambientales; la

${ }^{3}$ Ibidem, p. 75. 
estructura de la economía es irracional, caracterizada por una base agrícola débil y una falta de industria de punta; además, las compañías carecen de competitividad junto con la incapacidad de inversión de sus ganancias". ${ }^{4}$

Teniendo en cuenta este panorama, el gobierno chino propone un plan en dos etapas.

Primera etapa: 2011-2020

Como parte del cambio en el crecimiento económico, se tendrá que dar una innovación tecnológica en casa. Debido a que éstos serán los primeros años de reformas, es posible que se siga importando tecnología. Empero, dicho índice deberá ir decreciendo a medida que se invierta en nuevos sectores. Aquí podemos remitirnos a las siete industrias emergentes enunciadas en el XII Plan Quinquenal.

Segunda etapa: 2021-2030

En esta década será posible un mayor incremento de la dependencia hacia la tecnología doméstica. Tal situación debe estar acompañada de un intercambio tecnológico de las firmas chinas multinacionales y otras compañías nacionales, para que por medio de las redes internacionales se puedan copiar y mejorar modelos tecnológicos foráneos. Al final existirá una mayor consolidación de aquellas industrias chinas que están despuntando en la actualidad, como la eólica y la solar fotovoltaica.

Para cumplir con las estrategias planteadas, en 2011 el gobierno chino invirtió 1.84\% del PIB (es decir 7.46 billones de dólares, en I + D) en diversas áreas donde se espera que surja el nuevo potencial que catapultará a China en la economía mundial (cuadros 3 y 4).

CUADRO 3. Gasto en I + D por industria durante 2011

\begin{tabular}{|c|c|}
\hline Industria & Millones de dólares \\
\hline
\end{tabular}

${ }^{4}$ State Council from The People's Republic of China, The National Medium-and Long-Term Program for Science and Technology Development (2006-2020), Pekin, 2006, p. 8. 


\begin{tabular}{|l|c|}
\hline Fabricación de coque y productos de petróleo refinado & 1498.795 \\
\hline Fabricación de productos farmacéuticos básicos y preparados & 5062.214 \\
\hline Fabricación de metales básicos (cobre, plomo, zinc, plata y oro) & 16842.612 \\
\hline Industrias básicas de hierro y acero & 12284.867 \\
\hline Fabricación de metales no ferrosos y metales preciosos & 4557.745 \\
\hline Fabricación de productos metálicos (excepto maquinaria y equipo) & 2666.94 \\
\hline $\begin{array}{l}\text { Productos informáticos, electrónicos y ópticos. Equipos eléctricos, } \\
\text { maquinaria, vehículos de motor y otros materiales de transporte }\end{array}$ & 80393.022 \\
\hline Fabricación de productos informáticos, electrónicos y ópticos & 25447.335 \\
\hline Fabricación de equipo eléctrico & 14953.482 \\
\hline Fabricación de maquinaria y equipo & 18507.757 \\
\hline Información y comunicación & $4161.179(2009)$ \\
\hline Telecomunicaciones & $1029.275(2009)$ \\
\hline
\end{tabular}

FUENTE: Elaboración propia con datos de la OCDE, Science, Technology and Industry Outlook 2012, OECD, 2012, París.

CUADRO 4. Sectores de mayor inversión en I + D en 2011

\begin{tabular}{|l|l|c|}
\hline \multicolumn{1}{|c|}{ Empresa } & \multicolumn{1}{|c|}{ Sector de actividad } & $\begin{array}{c}\text { Inversión en } \\
\text { I+ D, en millones } \\
\text { de dólares }\end{array}$ \\
\hline Huawei Technologies & Equipos de telecomunicaciones & 2392 \\
\hline PetroChina & Petróleo y gas & 1774 \\
\hline China Railway Construction & Construcción y materiales & 1407 \\
\hline ZTE & Equipos de telecomunicaciones & 1188 \\
\hline China Petroleum \& Chemical & Petróleo y gas & 373 \\
\hline CSR China & Vehículos industriales & 80 \\
\hline
\end{tabular}

FUENTE: Elaboración propia con datos de la OCDE, Science, Technology and Industry Outlook 2012, OECD, 2012, París.

El Informe del Banco Mundial China 2030 prevé en el país asiático que mediante los sectores estratégicos es evidente el impulso y algunos beneficios que tendrán las tecnologías verdes, como el empleo (gráfica 1). 
GRÁFICA 1. Exportación de tecnologías y servicios verdes 2010-2030

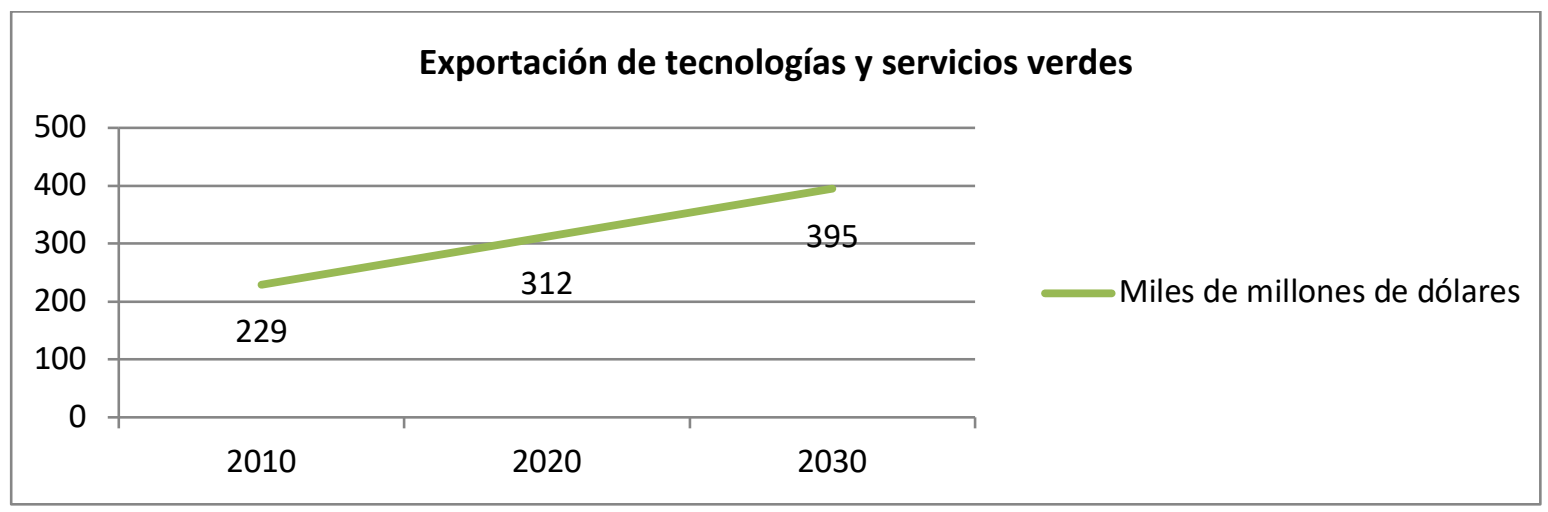

FUENTE: Elaboración propia con base en el informe del Banco Mundial, China 2030.

Los campos donde ahora compite China son telecomunicaciones, electrónica, automotriz, aeronáutica, y la joya de la corona: la industria aeroespacial. Sobre este último, cabe desatacar que el 28 de septiembre de 2008 China se convirtió en el tercer país en realizar navegación espacial, y ello fue posible sólo con inversión a largo plazo para el desarrollo de la tecnología adecuada. China ha establecido nuevos marcos de cooperación científicotecnológica con Brasil, Chile. Uruguay, Perú, Nicaragua, Bolivia, México, entre otros.

\section{ACUERDO DE ASOCIACIÓN ESTRATÉGICA:}

\section{INSTITUCIONALIZACIÓN DE LA RELACIÓN MÉXICO-CHINA}

En los últimos 15 años México y China han profundizado en sus relaciones diplomáticas que iniciaron el 14 de febrero de 1972. Sin duda son dos los derroteros que marcan la nueva relación entre ambas naciones. El primero es el ingreso de China a la OMC, que es un fuerte aliciente para este estrechamiento. Precisamente a partir de 2001 el vínculo comercial entre ambas naciones tuvo un giro de 180 grados, ya que es el eje multilateral el que determina el rumbo de la relación comercial entre ambas naciones. El segundo es a partir de 2013, cuando los entonces nuevos presidentes Enrique Peña y Xi Jinping le imponen un nuevo estilo a esta correlación.

Ambos mandatarios retoman figuras que a lo largo de este sinuoso camino se han ido construyendo, y las enmarcan en la Comisión Binacional México-China. Para los fines de 
este documento, es importante resaltar los mecanismos institucionales (algunos se han transformado) por los cuales ha transitado esta nueva realidad entre ambos países:

1. Grupo de Alto Nivel (GAN).

2. Subgrupo de Promoción del Comercio e Inversión.

3. Grupo sobre Medidas Sanitarias y Fitosanitarias.

4. Subgrupo de seguimiento a la lista de productos mexicanos con potencial de exportación a China.

5. Subgrupo sobre el Reconocimiento del Estatus Economía de Mercado de China.

6. Subgrupo de Cooperación Estadística.

7. Subgrupo sobre Promoción de Inversión Industrial.

8. Acuerdo para la Promoción y Protección Recíproca de las Inversiones.

9. Acuerdo de Promoción y Protección Recíproca de Inversión (APPRI).

10. Combate al Comercio Ilegal.

11. Asistencia Aduanera.

12. Cooperación Bancomext-Eximbank.

13. Acuerdos de doble tributación.

14. Acuerdo de cooperación minera.

Sin duda esta relación tiene dos grandes niveles, uno es el construido por los presidentes Xi y Peña, el cual ha abierto canales de comunicación antes vetados o inexistentes que se reflejan en diferentes niveles de cooperación (voluntad política) y deviene en el otro que es el económico, impulsado principalmente por dos actividades, comercial y de inversión, generado por la parte empresarial de ambos mercados (compromiso empresarial).

De los diferentes escalafones de diálogo que se han construido, el único jurídicamente fortalecido es el comercial, que se finca en el acuerdo que los dos países negociaron de manera bilateral en 2001 con el protocolo de adhesión de China a la OMC, el cual se pactó al amparo del artículo 1 del GATT de 1994, de la OMC; los demás son resultado precisamente de la comunicación abierta y fluida que los dos mandatarios han impulsado y que seguramente se transformarán en el momento en que abandonen el cargo.

Por ello, este documento propone que México debe institucionalizar jurídicamente estos mecanismos (figura 2) para que la relación no se finque únicamente en la parte comercial con la normatividad de la OMC (acuerdo de mercancías, acuerdo sobre derechos de 
protección a la propiedad intelectual relacionada con comercio, acuerdo de solución de diferencias). Para ello, ambas naciones deben denunciar la Cláusula de la Nación Más Favorecida y adoptar el Trato Nacional que establece la OMC, así como negociar un Acuerdo de Asociación Estratégica, que tendría tres niveles: a) político, b) de cooperación, y c) económico.

FIGURA 2

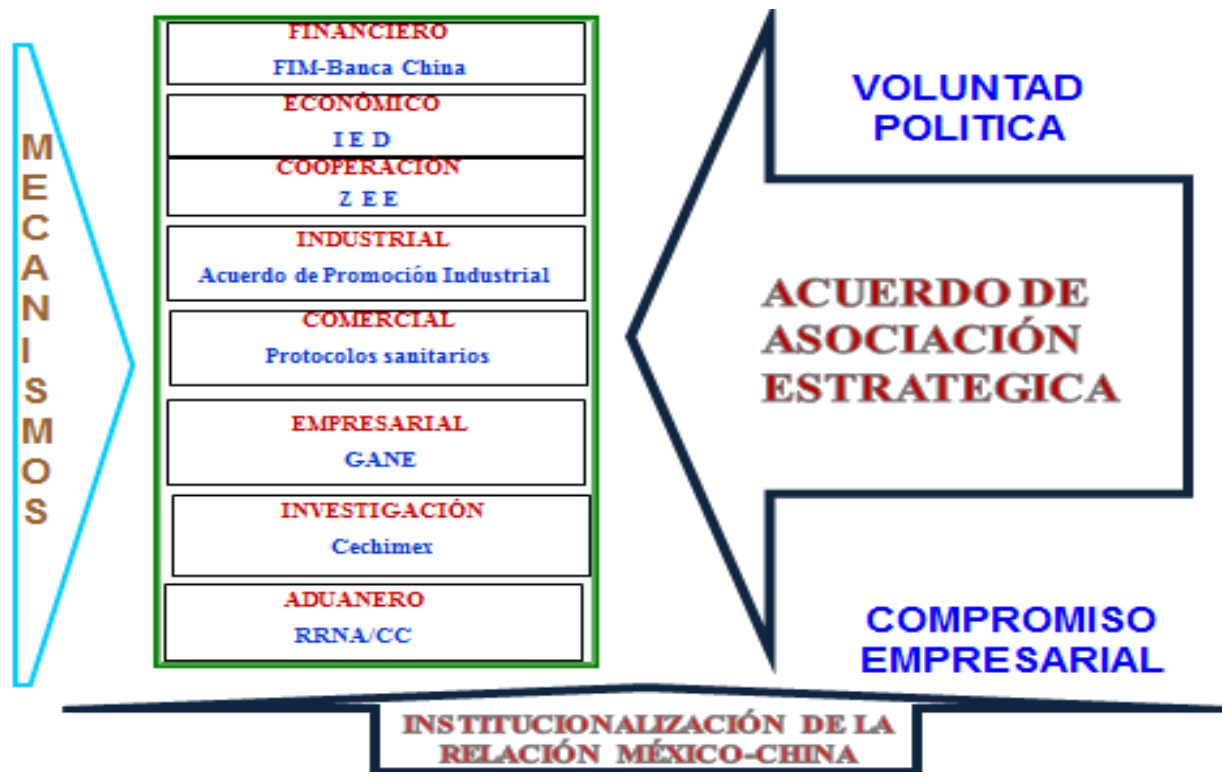

FUENTE: Elaboración propia.

Es por demás relevante destacar que a partir del 6 de febrero de 1996, la OMC ha ofrecido un nuevo marco jurídico para que los nuevos esquemas de negociación se construyan al amparo y regulación del nuevo artículo XXIV, el cual establece los Acuerdos Comerciales Regionales (ACR) que exentan a los países de extender lo negociado entre sí, a terceros países, por ende, ya no los sujeta a extender la cláusula de la Nación Más Favorecida (Martínez, 2013).

Como parte del marco de la Organización Mundial de Comercio, los ACR tienen un significado más amplio; pueden ser acordados por países que no comparten una región geográfica cercana. Los ACR pueden variar uno del otro, de hecho hoy en día tratan temas 
más allá de liberar el comercio entre Estados. ${ }^{5}$ La OMC permite que en los ACR se incluyan disposiciones que superen la regulación de materia comercial; en algunos se anexan normas en materia de inversión, medio ambiente, mano de obra y competencia económica, cooperación científica.

Los Acuerdos de Asociación no son tan completos como los Acuerdos de Libre Comercio, pero incluyen materias del ámbito político y de cooperación. De hecho, para ejemplificar podemos remitirnos al Acuerdo de Asociación Económica México-Japón, firmado en 2004, que incluye temas como: acceso al mercado de bienes, reglas de origen, certificados de origen, procedimientos aduaneros, normas sanitarias y fitosanitarias, salvaguardas, inversión, compras gubernamentales y solución de controversias. En este Acuerdo también se incluyó lo relacionado con pequeñas y medianas empresas, promoción al comercio y a la inversión, educación y tecnología, educación y capacitación laboral, turismo, propiedad intelectual, medio ambiente y mejoramiento al ambiente de negocios. ${ }^{6}$

Un Acuerdo de Asociación Estratégica tiene por objetivo fortalecer la relación bilateral en materia política, económica, comercial y de cooperación entre las partes, basada en la reciprocidad, el interés común, la complementariedad y la profundización de sus relaciones en todos los ámbitos de su aplicación. Además de que se establecen reuniones anuales al más alto nivel, teniendo un continuo diálogo político, fructífero y respetuoso de las normas de derecho internacional. De igual modo predomina el fortalecimiento de promoción en la inversión bilateral y la liberalización recíproca de los intercambios comerciales y la cooperación en los ámbitos educativo, científico, cultural y social.

Sin duda la diferencia entre un acuerdo de asociación económica y un acuerdo de asociación estratégica es que en el primero se negocian preferencias arancelarias sectoriales, y en el segundo los países miembros se otorgan recíprocamente un acceso aduanero preferencial por fracción arancelaria negociada, que se aplicará con referencia en el nivel arancelario que rija para terceros países. El acuerdo de asociación estratégica tiene como uno de sus fines la facilitación comercial entre las países negociantes, para reducir aranceles en distintos productos del sistema armonizado, por lo que deberá cumplir esencialmente con lo

${ }_{5}^{5}$ OMC. El ámbito de los ACR: URL: https://www.wto.org/spanish/tratop_s/region_s/scope_rta_s.htm (consultado el 19 de febrero de 2016).

6 Bancomext, El Acuerdo de Asociación Económica México-Japón: ¿Es posible un relanzamiento? URL: http://revistas.bancomext.gob.mx/rce/magazines/760/2/el_acuerdo_de_asociacion.pdf (consultado el 19 de febrero de 2016). 
establecido en los párrafos 5, 6, 7 y 8 del artículo XXIV del GATT, conforme al Entendimiento relativo a la interpretación del artículo XXIV del Acuerdo General de Aranceles Aduaneros y Comercio de 1994. Las partes contratantes están obligadas a presentar un plan y un programa para su establecimiento, manifestando qué sectores específicos son los interesados en dicho acuerdo.

En el párrafo 8 del artículo XXIV se hace alusión a la eliminación de reglamentaciones comerciales restrictivas, por lo que el AAE cumpliría con la esencia del artículo en cuanto a eliminar reglamentaciones restrictivas, no en todo el comercio entre ambas naciones, pero sí en sectores focalizados, donde se deberá establecer cuáles son las fracciones arancelarias beneficiadas con este trato.

Por su alcance, un Acuerdo de Asociación Estratégica entre México y China supera el marco de la OMC como única normatividad para tomarse como base en el proceso de institucionalización. El AAE tiene ejes más complejos, por lo que se deben tener en cuenta otros marcos legales internacionales en diversas áreas, como la política y la de cooperación. En este sentido, destaca la estrecha relación que ambas naciones tienen en foros internacionales, donde comparten posturas similares y en muchas ocasiones votan en el mismo sentido (figura 3 ).

Sin duda, a partir del 12 de diciembre de 2011 la sujeción entre México y China debe ser repavimentada mediante nuevas figuras que institucionalicen los canales de comunicación que los dos gobiernos han abierto entre sí, ya que la voluntad política del presidente Peña y del presidente Xi puede mermar cuando ambos, en sus respectivos periodos constitucionales, dejen el cargo. Por ello, en este documento se deja claro que se debe transitar a una nueva realidad que jurídicamente brinde un nuevo giro a esta relación. 


\section{FIGURA 3}

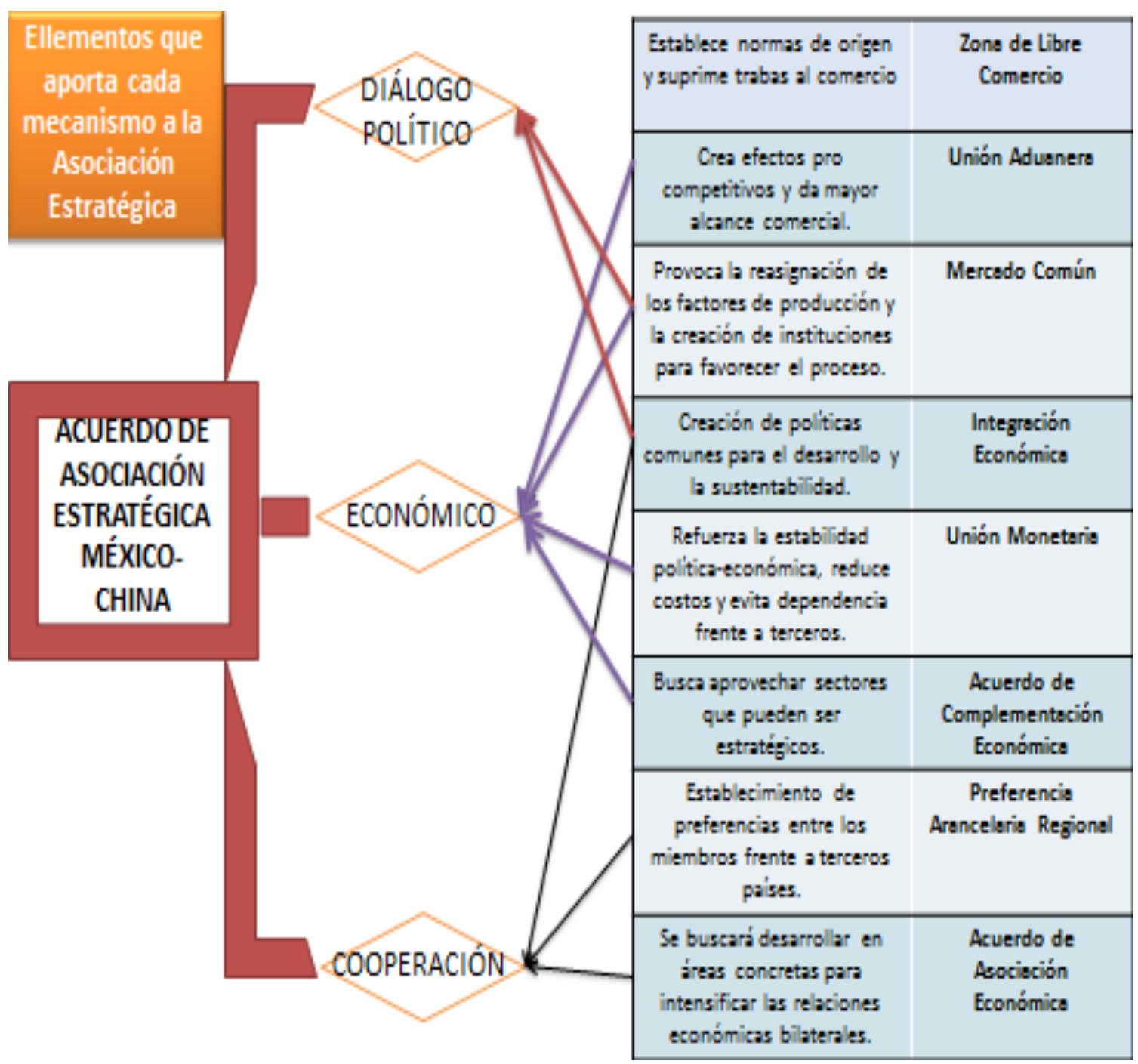

FUENTE: Elaboración propia.

\section{EL DESAFÍO DE DIGITALIZAR LA RELACIÓN COMERCIAL MÉXICO-CHINA}

Si bien, el establecimiento formal de la relación entre México y China tuvo lugar en 1972, no fue sino hasta inicios del nuevo siglo que este vínculo comenzó a adquirir un mayor dinamismo. Al respecto se distinguen dos factores que han impulsado la relación bilateral: el primero es el ingreso de China a la OMC, que coadyuvó a incrementar el comercio del país 
asiático y contribuyó a convertirlo, desde $2003,{ }^{7}$ en el segundo socio comercial de México, sólo después de Estados Unidos. El segundo factor está conformado por las reuniones de los presidentes Xi Jinping y Enrique Peña Nieto a partir de 2013, las cuales se han dirigido a fortalecer la relación en distintos ámbitos, enfatizando el comercio y la inversión.

Respecto a la relación comercial, durante la década de los noventa las importaciones que México realizaba desde China crecieron en promedio 38\% durante los diez años, y su valor promedio fue nueve veces mayor al de las exportaciones. Por otra parte, de 1990 a 1999 las exportaciones se incrementaron $70 \%$, aunque se registraron decrecientes en seis de los diez años.

Con el ingreso de China a la OMC, el comercio entre ambos países se incrementó de manera importante. Las exportaciones de México al país asiático crecieron 70\% de 2001 a $2002,{ }^{8}$ y desde ese año y hasta 2016 (año en que las exportaciones alcanzaron un valor de 5411 millones de dólares) el crecimiento promedio fue de $27 \%$. Por otra parte, las importaciones registraron un crecimiento de $56 \%$ de 2001 a 2002, y hasta 2016 el crecimiento promedio fue de 24\%, con lo que alcanzó, en ese último año, un valor de 69521 millones de dólares (doce veces superior al valor de las exportaciones).

De 2001 a 2016 las importaciones de China fueron en promedio trece veces superiores al valor de las exportaciones que se realizaron a este país asiático, por lo que la balanza comercial se registró deficitaria. Cabe mencionar que esta tendencia en la balanza comercial ya se presentaba en la década de los noventa, pero se acentuó con el incremento del comercio chino derivado de su ingreso a la Organización Mundial de Comercio.

${ }^{7}$ En 2003 las importaciones mexicanas de China superaron a las importaciones de Japón, por lo que este último país fue desplazado, en ese año, como segundo socio comercial de México.

${ }_{8}^{8}$ El mismo porcentaje de crecimiento (70\%) que había logrado en diez años (1990 a 1999), en el periodo anterior, lo había conseguido en tan sólo un año luego de ingresar a la Organización Mundial de Comercio. 
GRÁFICA 2. Comercio de México con China, 1990-2016

(millones de dólares)

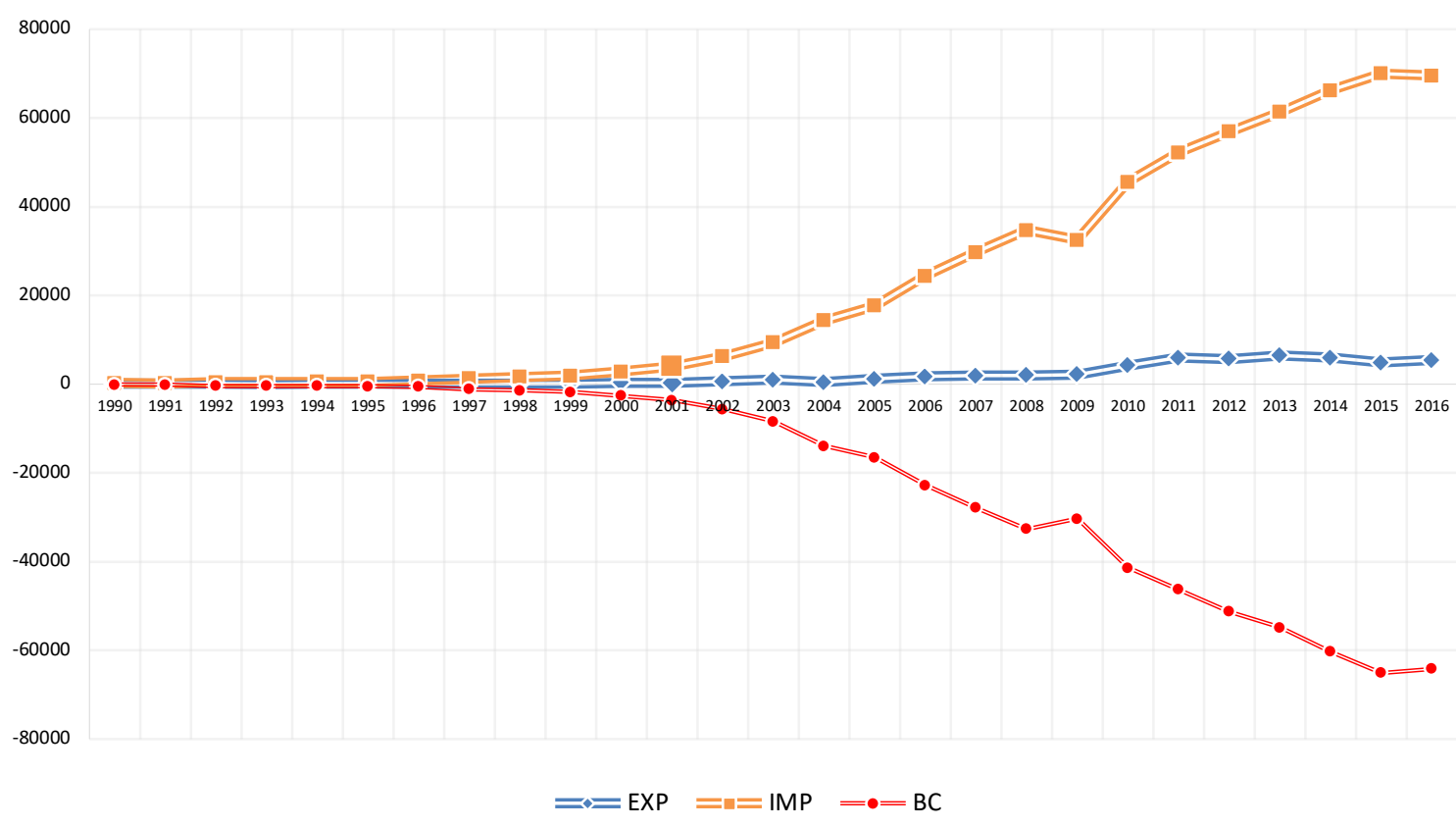

FUENTE: Elaboración propia con datos de UN Comtrade Database.

En lo referente al tipo de productos comercializados, en la segunda mitad de la década de los noventa, las exportaciones de México a China se caracterizaron por ser en su mayoría manufacturas y materias primas. Como se observa en la figura 4 , los productos del capítulo 84 del Sistema Armonizado de Designación y Codificación de Mercancías (SA) representaron $57 \%$ del total de las exportaciones; la subpartida $8473.30^{9}$ representó 99\% del comercio de este capítulo. Aunado a ello, en el periodo se comercializaron productos del capítulo 85 (el cual representó 4\% de las exportaciones), principalmente partes y accesorios de aparatos de emisión. Por otro lado, las materias primas para la industria textil, como los cables acrílicos o modacrílicos (capítulo 55) y los hilados de algodón (capítulo 52), representaron en conjunto $15 \%$ de las exportaciones mexicanas. A ello se le sumaron otro tipo de materias primas

${ }^{9}$ La subpartida 8473.30 incluye las “partes y accesorios de máquinas de la partida 84.71”, a la que corresponden las "máquinas automáticas para tratamiento o procesamiento de datos, analógicas o híbridas", principalmente ordenadores (SIAVI). Hasta el año 2000 el saldo de la balanza comercial que corresponde a esta subpartida se había mantenido superavitario, con un saldo de 62 millones de dólares; sin embargo, en 2001 registró un déficit de 66 millones de dólares, y desde ese año la balanza se registró negativa. 
pertenecientes a los capítulos 29 (productos químicos orgánicos), 39 (plásticos y sus manufacturas) y 26 (minerales metalíferos, escorias y cenizas) (figura 5).

FigurA 4. Principales capítulos del Sistema Armonizado en las exportaciones de México a China, 1995-2000

\begin{tabular}{|c|c|l|c|c|}
\hline No & $\begin{array}{c}\text { Capítulo } \\
(S A)\end{array}$ & \multicolumn{1}{|c|}{$\begin{array}{c}\text { Valor promedio } \\
\text { en el periodo } \\
1995-2000 \\
\text { millones } \\
\text { de dólares })\end{array}$} & $\begin{array}{c}\text { Porcentaje } \\
\text { en la } \\
\text { exportación } \\
\text { total }\end{array}$ \\
\hline 1 & 84 & $\begin{array}{l}\text { Reactores nucleares, calderas, máquinas, } \\
\text { aparatos y artefactos mecánicos; partes de } \\
\text { estas máquinas o aparatos }\end{array}$ & 62 & $57 \%$ \\
\hline 2 & 55 & $\begin{array}{l}\text { Fibras sintéticas o artificiales discontinuas } \\
\text { Algodón }\end{array}$ & 10 & $9 \%$ \\
\hline 4 & 73 & $\begin{array}{l}\text { Manufacturas de fundición, de hierro o de } \\
\text { acero }\end{array}$ & $6 \%$ \\
\hline 5 & 85 & $\begin{array}{l}\text { Máquinas, aparatos y material eléctrico y sus } \\
\text { partes; aparatos de grabación o reproducción } \\
\text { de sonido, aparatos de grabación o } \\
\text { reproducción de imágenes y sonido en } \\
\text { televisión, y las partes y accesorios de estos } \\
\text { aparatos }\end{array}$ & 5 & $5 \%$ \\
\hline
\end{tabular}

FUENTE: Elaboración propia con datos de UN Comtrade Database.

Con el ingreso de China a la OMC, las exportaciones mexicanas hacia ese país comenzaron a presentar cambios. Tal como se puede observar en la figura 5, en el periodo de 2001 a 2016 el capítulo 26 fue el de mayor participación porcentual en las exportaciones, con casi una cuarta parte. La subpartida 2603.00 representó el $100 \%$ del comercio de este capítulo.

Es fundamental tener en cuenta que la subpartida 2603.00 corresponde a los minerales de cobre y sus concentrados, y que sumada a las exportaciones del capítulo 74 (en las que se destacó la subpartida 7403.11, que corresponde a placas (cátodos) de cobre), representan el $35 \%$ del comercio. Esta consideración es relevante debido a que las propiedades del cobre (principalmente la de conductividad eléctrica) lo convierten un metal de importante uso en 
las industrias eléctrica y de telecomunicaciones, las cuales han sido altamente desarrolladas en China.

La exportación de productos de la industria automotriz (capítulo 87) también registró un crecimiento en este periodo. El comercio de estos productos representó el 20\% del total de las exportaciones, en las cuales se destacaron los vehículos de las subpartidas 8703.23 (de cilindrada superior a $1500 \mathrm{~cm}^{3}$, pero inferior o igual a $3000 \mathrm{~cm}^{3}$.) y 8703.24 (De cilindrada superior a $3000 \mathrm{~cm}^{3}$ ). Cabe mencionar que la balanza comercial de ambas subpartidas se ha registrado superavitaria desde 2006.

Por su parte, los productos de mayor valor, como los de los capítulos 85 y 84, llegaron a representar en el periodo el 9\% del total de las exportaciones cada uno. Del capítulo 85, se destacó la subpartida $8517.62^{10}$, y del capítulo 84 la subpartida $8471.30 .{ }^{11}$ Cabe destacar que la balanza de estos capítulos fue deficitaria en el periodo. (SIAVI)

${ }^{10}$ La subpartida 8517.62 incluye los "aparatos para la recepción, conversión y transmisión o regeneración de datos" ${ }^{11}$ La subpartida 8471.30 corresponde a las "máquinas automáticas para tratamiento o procesamiento de datos, digitales, portátiles, de peso inferior o igual a $10 \mathrm{~kg}$, que estén constituidas, al menos, por una unidad central de proceso, un teclado y un visualizador" (SIAVI). 
FiguRA 5. Principales capítulos del Sistema Armonizado en las exportaciones de México a China, 2001-2016

\begin{tabular}{|l|c|l|c|c|}
\hline & & & $\begin{array}{c}\text { Valor } \\
\text { promedio en } \\
\text { el periodo } \\
\text { 2001-2016 } \\
\text { (millones de } \\
\text { dólares) }\end{array}$ & $\begin{array}{c}\text { Porcentaje en } \\
\text { la exportación } \\
\text { total }\end{array}$ \\
\hline No & $\begin{array}{c}\text { Capitulo } \\
(\text { SA })\end{array}$ & \multicolumn{1}{|c|}{ Descripción } & 738 & $24 \%$ \\
\hline 1 & $\mathbf{2 6}$ & Minerales metalíferos, escorias y cenizas & 611 & $20 \%$ \\
\hline 3 & $\mathbf{8 7}$ & $\begin{array}{l}\text { Vehículos automóviles, tractores, ciclos y demás } \\
\text { vehículos terrestres, sus partes y accesorios }\end{array}$ & $11 \%$ \\
\hline 4 & $\mathbf{8 5}$ & $\begin{array}{l}\text { Cobre y sus manufacturas } \\
\text { aparquinas, aparatos y material eléctrico y sus partes; } \\
\text { aparatos de grabación o reproducción de sonido, } \\
\text { y sonido en televisión, y las partes y accesorios de } \\
\text { estos aparatos }\end{array}$ & 294 & $9 \%$ \\
\hline 5 & $\mathbf{8 4}$ & $\begin{array}{l}\text { Reactores nucleares, calderas, máquinas, aparatos y } \\
\text { artefactos mecánicos; partes de estas máquinas o } \\
\text { aparatos }\end{array}$ & 281 & $9 \%$ \\
\hline
\end{tabular}

FUENTE: Elaboración propia con datos de UN Comtrade Database.

En lo concerniente a las importaciones, en 1995 China figuraba en el doceavo lugar como socio de México, y para el año 2000 ya ocupaba el sexto lugar. En este periodo, 30\% de las importaciones estuvieron conformadas por productos del capítulo 85, aunque destaca la partida 8527. ${ }^{12}$ Asimismo, otros productos de valor agregado, como las unidades de entrada y salida ${ }^{13}$ (en su mayoría para ordenadores) que pertenecen al capítulo 84, así como las cámaras fotográficas de la subpartida 9006.91 (capítulo 90), figuraron entre los principales productos importados (figura 6).

\footnotetext{
12 La partida 8527 está conformada por los "aparatos receptores de radiotelefonía, radiotelegrafía o radiodifusión, incluso combinados en la misma envoltura (gabinete, carcasa), con grabador o reproductor de sonido o con reloj" (SIAVI).

${ }^{13}$ En su mayoría pertenecientes a la subpartida 8471.60 "Unidades de entrada o salida, aunque incluyan unidades de memoria en la misma envoltura (gabinete, carcasa)" (SIAVI).
} 
FIGURA 6. Principales capítulos del Sistema Armonizado en las importaciones mexicanas de China, 1995-2000

\begin{tabular}{|c|c|c|c|c|}
\hline No & $\begin{array}{c}\text { Capítulo } \\
\text { (SA) }\end{array}$ & Descripción & $\begin{array}{c}\text { Valor } \\
\text { promedio } \\
\text { en el } \\
\text { periodo } \\
\text { 1995-2000 } \\
\text { (millones } \\
\text { de dólares) }\end{array}$ & $\begin{array}{l}\text { Porcentaje } \\
\quad \text { en la } \\
\text { importación } \\
\text { total }\end{array}$ \\
\hline 1 & 85 & $\begin{array}{l}\text { Máquinas, aparatos y material eléctrico y sus } \\
\text { partes; aparatos de grabación o reproducción de } \\
\text { sonido, aparatos de grabación o reproducción } \\
\text { de imágenes y sonido en televisión, y las partes } \\
\text { y accesorios de estos aparatos }\end{array}$ & 450 & $30 \%$ \\
\hline 2 & 84 & $\begin{array}{l}\text { Reactores nucleares, calderas, máquinas, } \\
\text { aparatos y artefactos mecánicos; partes de estas } \\
\text { máquinas o aparatos }\end{array}$ & 204 & $14 \%$ \\
\hline 3 & 95 & $\begin{array}{l}\text { Juguetes, juegos y artículos para recreo o para } \\
\text { deportes; sus partes y accesorios }\end{array}$ & 135 & $9 \%$ \\
\hline 4 & 90 & $\begin{array}{l}\text { Instrumentos y aparatos de óptica, fotografía o } \\
\text { cinematografía, de medida, control o de } \\
\text { precisión; instrumentos y aparatos médico- } \\
\text { quirúrgicos; partes y accesorios de estos } \\
\text { instrumentos o aparatos }\end{array}$ & 71 & $5 \%$ \\
\hline 5 & 27 & $\begin{array}{l}\text { Combustibles minerales, aceites minerales y } \\
\text { productos de su destilación; materias } \\
\text { bituminosas; ceras minerales }\end{array}$ & 59 & $4 \%$ \\
\hline
\end{tabular}

FUENTE: Elaboración propia con datos de UN Comtrade Database.

Como puede observarse en la gráfica 2, las importaciones de China comenzaron a incrementarse de manera significativa a partil de 2001, y para 2016 aumentaron $1626 \%$ su valor (al pasar de 4027 millones de dólares en 2001, a 69521 millones en 2016).

Durante este periodo, $43 \%$ de las importaciones fueron productos del capítulo 85 , aunque destaca la subpartida 8517.12, que incluye principalmente teléfonos celulares. Aunado a ello, los productos del capítulo 84 representaron 23\%, aunque destacan las unidades de memoria de la subpartida 8471.70. Por otra parte, en una menor proporción de crecimiento, la importación de los productos del capítulo 90 (de los cuales se destacó la 
partida 9013 que incluye los dispositivos de cristal líquido) llegó a representar 4\% en el periodo.

Si bien las partidas y subpartidas mencionadas no representaron el $100 \%$ de cada capítulo, sí fueron las de mayor participación. Los tres capítulos corresponden a productos de alto valor agregado, y en este periodo representaron en conjunto $70 \%$ de las importaciones mexicanas de China (figura 7).

FIgURA 7. Principales capítulos del Sistema Armonizado en las importaciones mexicanas de China, 2001-2016

\begin{tabular}{|c|c|c|c|c|}
\hline No & $\begin{array}{c}\text { Capitulo } \\
\text { (SA) }\end{array}$ & Descripción & $\begin{array}{l}\text { Valor } \\
\text { promedio en } \\
\text { el periodo } \\
1995-2000 \\
\text { (millones de } \\
\text { dólares) }\end{array}$ & $\begin{array}{l}\text { Porcentaje } \\
\quad \text { en la } \\
\text { importación } \\
\quad \text { total }\end{array}$ \\
\hline 1 & 85 & $\begin{array}{l}\text { Máquinas, aparatos y material eléctrico y sus } \\
\text { partes; aparatos de grabación o reproducción } \\
\text { de sonido; aparatos de grabación o } \\
\text { reproducción de imágenes y sonido en } \\
\text { televisión, y las partes y accesorios de estos } \\
\text { aparatos }\end{array}$ & 16015 & $43 \%$ \\
\hline 2 & 84 & $\begin{array}{l}\text { Reactores nucleares, calderas, máquinas, } \\
\text { aparatos y artefactos mecánicos; partes de } \\
\text { estas máquinas o aparatos }\end{array}$ & 8629 & $23 \%$ \\
\hline 3 & 90 & $\begin{array}{l}\text { Instrumentos y aparatos de óptica, fotografía o } \\
\text { cinematografía, de medida, de control o de } \\
\text { precisión; instrumentos y aparatos médico- } \\
\text { quirúrgicos; partes y accesorios de estos } \\
\text { instrumentos o aparatos }\end{array}$ & 1554 & $4 \%$ \\
\hline 4 & 95 & $\begin{array}{l}\text { Juguetes, juegos y artículos para recreo o para } \\
\text { deportes; sus partes y accesorios }\end{array}$ & 1185 & $3 \%$ \\
\hline 5 & 39 & Plástico y sus manufacturas & 920 & $2 \%$ \\
\hline
\end{tabular}

FUENTE: Elaboración propia con datos de UN Comtrade Database. 


\section{MÉXICO FRENTE A CHINA EN EL IMPULSO A LA PRODUCCIÓN DE BIENES DE ALTA TECNOLOGÍA}

China ha realizado esfuerzos significativos para transformar su estructura productiva basada en manufacturas, a una estructura basada en productos de alto valor agregado. Esta transformación se ha ido logrando con base en las políticas y normatividades que fomentan el desarrollo desde una nueva visión, en la que la innovación desempeña un papel principal.

El marco institucional que fomenta esta nueva visión encuentra sus bases en el establecimiento de la reforma de apertura china, en 1978, y en el planteamiento de las Cuatro Grandes Modernizaciones, en las que se incluyó el desarrollo de la ciencia y la tecnología. Asimismo, en el VI Plan Quinquenal (1980-1985) comenzaron a formarse los fundamentos para la construcción de un sistema científico-tecnológico, y en los posteriores planes se estructuraron los lineamientos para la constitución de un sistema de innovación.

Aunado a los planes quinquenales, que precisan los principales objetivos de la nación, el gobierno de China puso en marcha diversas normatividades encaminadas a fortalecer el sistema de innovación, tales como el Programa 863, el Plan Chispa, el Programa Antorcha, el Programa 211, y el Plan Estatal del Desarrollo Científico y Tecnológico a Mediano y Largo Plazos (2006-2020), entre otros.

Si bien China ha impulsado una gran cantidad de instituciones dirigidas al fomento de una nueva visión de desarrollo basada en la innovación, el Gobierno Central considera la iniciativa Made in China 2025 como la clave para lograr la completa trasformación de la estructura de producción en el siglo XXI. Por medio de esta iniciativa se pretende "aumentar la calidad de la producción mediante la aplicación de nuevos estándares, automatización y tecnologías inteligentes, a la vez que se hace hincapié en la producción sostenible" (Gómez Pérez-Cuadrado, 2016: 4).

En esa misma línea de acción, China se ha encargado de impulsar el desarrollo de las empresas, tanto pequeñas como medianas y grandes, al tiempo que fomenta la inversión en educación superior, promueve el establecimiento de centros de investigación e incrementa la inversión en I + D. 
En el caso de México, los esfuerzos por impulsar el desarrollo de la ciencia y la tecnología se han mostrado endebles. Al respecto, el Plan Nacional de Desarrollo del actual sexenio (2013-2018) estableció como objetivo 3.5 hacer de los desarrollos científico, tecnológico y de innovación los pilares para el progreso económico y social sostenible.

Aunado a ello, en 2014 se presentó el Programa Especial de Ciencia, Tecnología e Innovación 2014-2018, en el cual se argumentó tener como propósito principal "lograr que la sociedad mexicana se apropie del conocimiento científico y tecnológico y lo utilice para ser más innovadora y productiva" (Conacyt, 2014). Este programa buscaba robustecer el Sistema Nacional de Ciencia, Tecnología e Innovación mediante la inversión en ámbitos estratégicos, para incrementar la producción científico-tecnológica.

Si bien en el Plan Nacional de Desarrollo y en el Programa Especial de Ciencia, Tecnología e Innovación se incluyen parámetros como el impulso a las instituciones de educación superior, la construcción de infraestructura de innovación y el fortalecimiento del capital humano, lo cierto es que no se han estructurado normatividades más específicas para hacer cumplir dichos objetivos.

En lo concerniente al comercio, específicamente a las exportaciones (una de las bases fundamentales de la economía mexicana), México es actualmente uno de los principales países de América Latina, junto con Brasil, que ha incrementado sus exportaciones de productos de alta tecnología. No obstante, ante la falta de desarrollo de estrategias y normatividades concretas que estén dirigidas al impulso de la ciencia, tecnología e innovación, el comercio de productos de alta tecnología se ve limitado. De hecho, en México la balanza comercial de estos productos se encuentra en déficit.

Como puede observarse en la gráfica 3 , si se compara la exportación de productos de alta tecnología de México y China, las exportaciones mexicanas se encuentran muy por debajo de las exportaciones chinas. Mientras las exportaciones de México crecieron 57\% de 2001 a 2016, las exportaciones de China se incrementaron 904\%, como resultado de las políticas y normatividades de impulso y fomento a la innovación, la ciencia y la tecnología. 
GRÁFICA 3. Exportación de productos de Alta Tecnología

(millones de dólares)

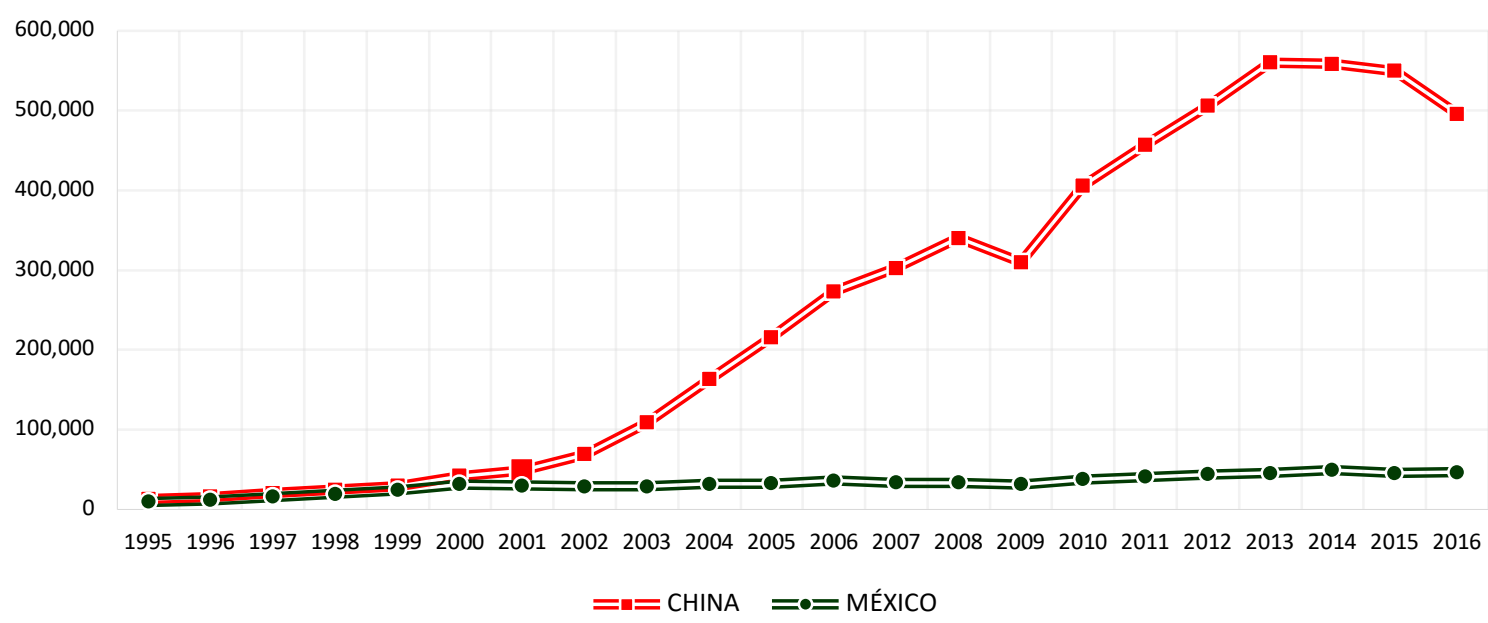

FUENTE: Elaboración propia con datos de Banco Mundial, High-Technology exports. 
FIGURA 8. Digitalización de la relación México-China mediante dos vías

Figura 1. Digitalizar la relación México-China mediante dos vías

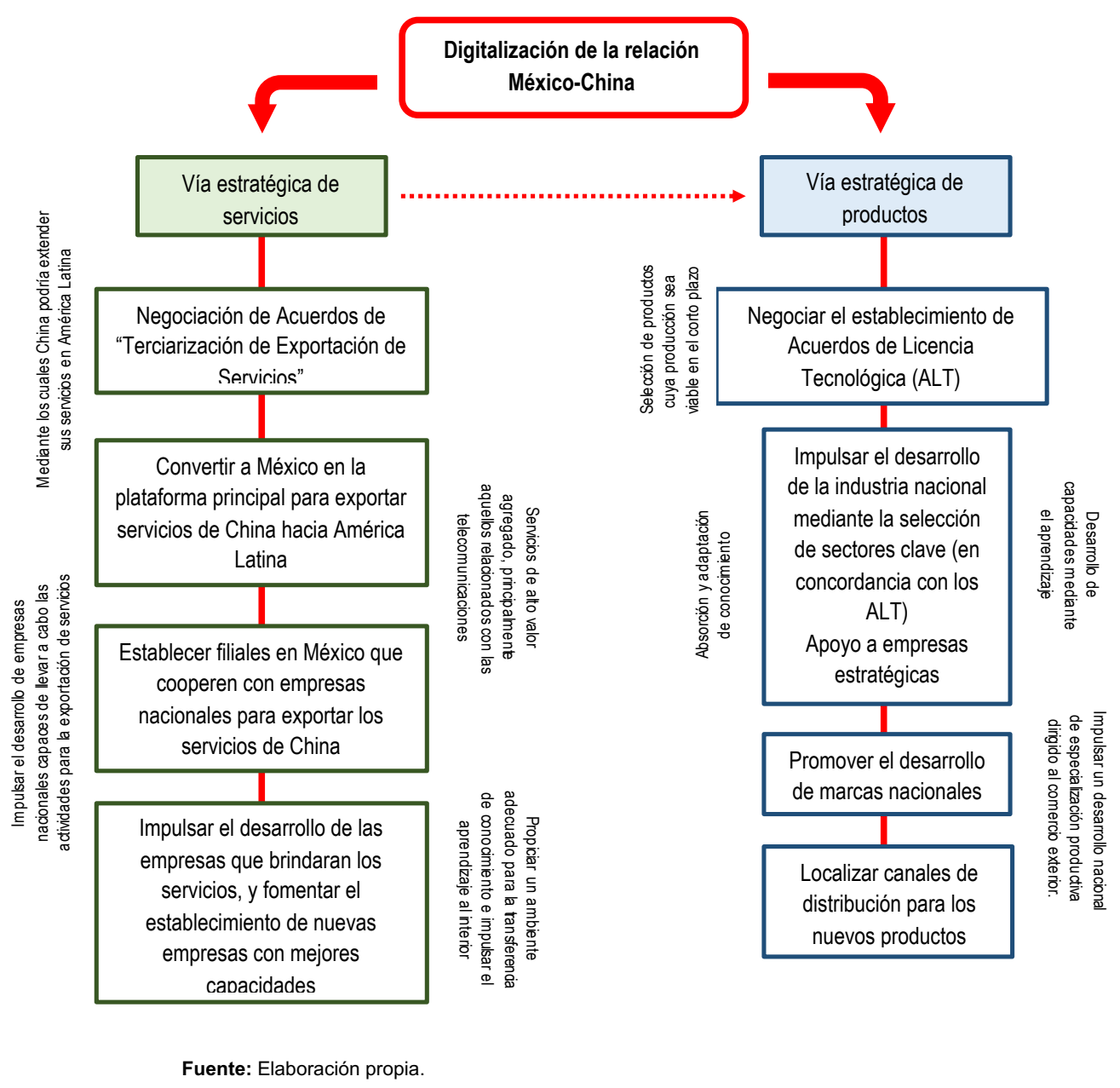

FUENTE: Elaboración propia.

\section{CONCLUSIÓN}

Con base en mecanismos económicos, Estados Unidos ha emprendido una lucha por la supremacía tecnológica con China. La nueva visión de desarrollo basada en la innovación, ha colocado a la tecnología como un factor de poderío, presente en el ámbito económico (como base de la fabricación), político (como mecanismo de difusión y comunicación), social (para la creación de redes) y militar (para el desarrollo de sistemas avanzados de armamento). 
Sin embargo, la economía en el sistema internacional es frágil, y al utilizar el comercio como herramienta de presión se pone en riesgo la estabilidad económica y por tanto el bienestar social a escala global.

La naturaleza del enfrentamiento hace difícil que se perciban resultados favorables. Como se ha expuesto, sectores importantes de la economía internacional serán afectados por la imposición de tarifas, vislumbrándose como beneficio el desarrollo de capacidades al interior de cada país en respuesta a la reducción de la oferta y demanda, o al incremento de precios, de productos entre ambas naciones.

Considerando la fractura en la relación comercial China-Estados Unidos, puede presentarse la posibilidad de que los mismos sectores afectados en estas naciones (alta tecnología, industrial, agrícola, automotriz, energético, etc.) sean impulsados por otros países que intentaran satisfacer la demanda con una oferta más accesible. Sin embargo, ese reemplazo tardaría un tiempo considerable.

La iniciativa Made in China 2025 está dirigida a incrementar el nivel de producción nacional en la cadena de valor (pasar de la producción de gama baja a la de gama alta), y a colocar al país como líder tecnológico a escala internacional. Con ello, el gobierno de China pretende reducir la dependencia tecnológica que tiene con Estados Unidos, impulsando industrias estratégicas (como conductores y semiconductores).

Esta iniciativa y la intención de China de convertirse en el líder tecnológico mundial se consideran un riesgo para la seguridad económica de Estados Unidos, ya que China podría llegar a producir de manera independiente los bienes y servicios en los que hoy Estados Unidos es líder, y colocarlos tanto en su mercado interno como alrededor del mundo, desplazando así a las empresas estadounidenses, paulatinamente, con una gama de productos más competitivos, y creando un posible escenario donde la dependencia tecnológica se invertiría y Estados Unidos incrementaría su déficit.

Asimismo, se ha afirmado la necesidad de evitar las adquisiciones de empresas estratégicas (principalmente de telecomunicaciones) para impedir que las empresas estadounidenses que brindan servicios de alto nivel sean reemplazadas por las empresas chinas que ofrecen esos mismos servicios, lo cual contribuiría a la reducción de la dependencia tecnológica, así como al incremento de la expansión china. 
En este sentido, la guerra comercial está dirigida a evitar el incremento de capacidades tecnológicas de China que podrían convertir al país en el líder económico internacional, y a reducir las ventajas de Estados Unidos dentro de un sistema mundial cuyo desarrollo cada vez está más enfocado en la economía digital. Cabe mencionar que el desarrollo tecnológico no sólo está dirigido al consumo, sino que también tiene un papel importante en el ámbito militar, por lo que el ascenso tecnológico de China implicaría también una mejora en sus recursos bélicos y, por tanto, una reducción de las capacidades de coacción estadounidenses.

China ha realizado esfuerzos significativos para transformar su estructura productiva basada en manufacturas, a una estructura basada en productos de alto valor agregado. Esta transformación se ha ido logrando con base en las políticas y normatividades que fomentan el desarrollo desde una nueva visión, en la que la innovación ha desempeñado un papel principal.

Con lo anteriormente expuesto, resulta evidente la imperiosa necesidad que tiene México de emprender acciones dirigidas a generar el desarrollo de sus capacidades científicotecnológicas y de innovación. En comparación fortalecer el sistema nacional de innovación son mínimos. Así, las oportunidades de incrementar un comercio bilateral basado en productos de valor agregado están limitadas para México, ya que el país asiático tiene un alto poder de desarrollo de estos productos, frente a los cuales la producción mexicana no podría competir.

Si México pretende digitalizar la relación bilateral, entendiendo exte concepto como la evolución de la relación comercial, que pasa de basarse en productos de gama baja a un intercambio de productos de gama alta, debe ejecutar de inmediato acciones concretas dirigidas a optimizar, en primer lugar, su industria nacional, para después impulsar sus relaciones comerciales en el exterior.

En vista de la carencia de complementariedad productiva que existe entre México y China, y considerando el desarrollo de servicios de alto valor que se ha generado en el país asiático, se plantea la vía estratégica de servicios, en la que México podría apostar por convertirse en una plataforma de exportación de servicios de alto valor agregado (principalmente telecomunicaciones) de empresas chinas, cuyo mercado sería América Latina. Es decir, mediante el establecimiento de una normatividad bilateral que impulse la tercerización de exportaciones, las empresas chinas de servicios, de alto valor agregado, 
podrían establecer filiales en México que cooperen y se organicen con aquellas empresas mexicanas capaces de llevar a cabo las actividades de exportación de estos servicios.

Esta vía impulsaría la relación bilateral en tanto que contribuiría a extender el mercado de servicios de China, y crearía oportunidades de internacionalización y aprendizaje para las empresas mexicanas.

Por otro lado, se plantea la vía estratégica de productos, en la que el principal objetivo de México es desarrollar las capacidades científico-tecnológicas de producción.

Mediante el establecimiento de los ALT México podría intensificar el desarrollo de la industria nacional y crear un ambiente propicio para la absorción y adaptación del conocimiento, que deriven en la creación de nuevas marcas nacionales que a su vez puedan ser integradas al comercio exterior, mediante una búsqueda adecuada de canales de distribución potenciales.

Estas dos vías deben ir acompañadas de un cambio en las políticas de educación, industria e inversión, las cuales deberán promover iniciativas de cambio que conduzcan a la construcción de una nueva visión de desarrollo basada en el impulso de las capacidades científico-tecnológicas y de innovación.

\section{REFERENCIAS BIBLIOGRÁFICAS}

Barnet, Richard y John Cavanagh (1994), Global Dreams. Imperial Corporations and the New World Order, Touchstone, Nueva York, Simon and Schuster.

Best, Michael (1990), The New Competition. Institutions of Industrial Restructuring, Cambridge, Harvard Press.

Bustelo, Pablo y Yolanda Lommen (1996), La economía china ante el siglo XXI. Veinte años de reforma, Madrid, Síntesis.

Gómez Pérez-Cuadrado Esther (2016), Plan Made in China 2025. Disponible en: https://www.icex.es/icex/es/navegacion-principal/DOC2016671546.pdf

Lester, Thurow (1992), La guerra del siglo XXI, Buenos Aires, Vergara. 
Martínez, I. (2013), "Las reglas de origen: instrumento para regular las zonas comerciales regionales con Acceso Arancelario Preferencial", Revista de Relaciones Internacionales, México, UNAM.

OCDE (2012), Science, Technology and Industry Outlook 2012, París, OECD.

OCDE (2013), Economic Surveys: China 2013, París, OCDE.

Rich, Robert (1992), The Work of the Nations, Washington, Vintage Books.

World Bank (2012), China 2030. Building a Modern, Harmonious and Creative Society, Washignton World Bank Press. 